\title{
DISOPYRAMIDE PHARMACOKINETICS AND BIOAVAILABILITY
}

Disopyramide [diisopropylamino-2-phenyl-2-(2-pyridyl) butyramide] is a cardiac antiarrhythmic agent which is coming into increasing use clinically. The drug has been given orally either as the free base or as the phosphate salt, while the phosphate is available for parenteral use.

A study of the bioavailability of disopyramide in these three preparations has been carried out.

The following disopyramide preparations were studied:

(i) capsules of disopyramide phosphate (Searle Laboratories), with a total nominal $100 \mathrm{mg}$ content (as the salt).

(ii) capsules of disopyramide base (Roussel Laboratories), with a nominal content of $100 \mathrm{mg}$ (as the base).

(iii) ampoules of disopyramide phosphate (Searle Laboratories), with a nominal content of $100 \mathrm{mg}$ (as the base).

The actual contents of disopyramide base in randomly selected dosage units from the same batches of the preparations as those used in the present study were independently assayed by Searle Laboratories. Mean values were:

(i) $92.0 \mathrm{mg} \quad$ (ii) $103.6 \mathrm{mg}$ (iii) $99.2 \mathrm{mg}$.

These actual values were used in the bioavailability calculations.

Seven healthy adult male volunteers, aged between 19 and 29 years, and weighing between 68.5 and $87.1 \mathrm{~kg}$, participated in the investigation. Prior to study all subjects underwent clinical examination, ECG and haematological and biochemical screening. The only abnormality occurred in subject 7, who had a right bundle branch block in his ECG. He did not receive disopyramide intravenously, though he received the two oral preparations of disopyramide.

After an overnight fast each subject received a nominal $100 \mathrm{mg}$ disopyramide as one of the three preparations studied. The intravenous preparation was injected over $1 \mathrm{~min}$, with ECG monitoring of the recumbent subjects. The oral preparations were taken with $150 \mathrm{ml}$ water. No food was taken for at least a further $4 \mathrm{~h}$ though the subjects were permitted up to $150 \mathrm{ml}$ of water per hour. No alcohol was taken for $24 \mathrm{~h}$ prior to the study or during the blood collection period. Subjects were ambulant during the greater part of the studies. Blood for disopyramide measurement was collected at the following times: $0 ; 0.25 ; 0.50 ; 1.0$; $2.0 ; 3.0 ; 4.0 ; 6.0 ; 8.0 ; 12.0 ; 24.0 \mathrm{~h}$ (collection at $0.25 \mathrm{~h}$ occurred after intravenous administration only).

At intervals of not less than 1 week the procedure was repeated twice, each subject receiving a different preparation on the subsequent occasions. The order of administration of the preparations was randomized.
An attempt was made to use the gas chromatographic assay of Hutsell \& Stachelski (1975), but this method proved insufficiently sensitive due to an interfering peak which coincided with disopyramide. This peak was traced to di-2-ethylhexyl-phthalate, a plasticizer which was also found in Blood Bank bags and blood (a finding similar to that of Jaeger \& Rubin, 1972; Marcel \& Noel, 1972 and Ono, Tatsukawa \& Wakimoto, 1975) as well as in plastic tubing and test tube caps. This plasticizer could not be extracted from plastic syringes or polypropylene blood collection tubes (lacking ballotini beads).

Once the role of the plasticizer was recognized a simplified assay was developed, using all glass systems.

Plasma was separated from formed elements of blood by centrifuging. Plasma $(2 \mathrm{ml})$ and $2 \mathrm{ml} 0.2 \mathrm{M}$ phosphate buffer (pH 7.2) were added to $10 \mathrm{ml}$ chloroform containing $2.5 \mu \mathrm{g} p$-chlorodisopyramide as internal standard. After mixing, the aqueous layer was aspirated and the organic layer transferred to another tube in which it was evaporated to dryness. The residue was redissolved in chloroform, and $1.5 \mu \mathrm{l}$ was injected into a Varian gas chromatograph fitted with a glass column packed with $3 \%$ SE-30 on Chromosorb G $(80-100$ mesh). By use of flame ionization detection and the following operating conditions peaks for disopyramide and internal standard occurred with retention times of $3.4 \mathrm{~min}$ and $6.0 \mathrm{~min}$ respectively: Carrier gas-helium, flow $60 \mathrm{ml} / \mathrm{min}$, injection port $235^{\circ} \mathrm{C}$, column $225^{\circ} \mathrm{C}$ \& detector $235^{\circ} \mathrm{C}$.

The calibration curve for the assay was linear over the concentration range 0.4 to $10.0 \mu \mathrm{g} / \mathrm{ml}$, and intersected the origin. The correlation coefficient was 0.98 . Over the concentration range studied the assay was reproducible within $\pm 0.3 \mu \mathrm{g} / \mathrm{ml}$.

The plasma disopyramide concentration data fitted quite adequately a one-compartment open pharmacokinetic model and were analysed in terms of this model. After semilogarithmic transformation, postabsorption phase data were analysed by least squares linear regression techniques, using a Hewlett Packard Model 9810 programmable calculator, to define the elimination rate constant (k). An attempt was made to use the technique of 'feathering' to determine absorption parameters, but insufficient plasma level measurement had been obtained in the absorption phase for accurate calculation. Time to attain maximum plasma levels $\left(T_{\max }\right)$ was read from the graphs. Areas under the plasma level curves to $24 \mathrm{~h}$ $\left(\mathrm{AUC}_{0-24}\right)$ were determined by the technique of cutting out and weighing, and areas under the curves from $24 \mathrm{~h}$ to infinity (AUC $\mathrm{AU}_{24} \rightarrow \infty$ ) were determined by dividing the plasma level at $24 \mathrm{~h}$ by the elimination rate constant (k) (Gibaldi \& Perrier, 1975). Clearances 
were calculated by dividing $\mathrm{AUC}_{0 \rightarrow \infty}$ into the drug dose given. Apparent volume of distribution was derived from the product of clearance and $k$. The best estimates of these parameters were derived from the intravenous data.

There were no adverse reactions to the drug in any subject.

The time courses of the mean plasma disopyramide levels produced by the three preparations are shown in Figure 1.

The various calculated pharmacokinetic parameters are set out in Table 1.

There were no statistically significant differences between the mean elimination rate constants obtained when disopyramide was given in the different preparations under study $\left(0.1099 \pm 0.0405 \mathrm{~h}^{-1}\right.$ for the intravenous preparation; $0.1045 \pm 0.0267 \mathrm{~h}^{-1}$ for the oral phosphate; $0.1064 \pm 0.0183 \mathrm{~h}^{-1}$ for the oral base). Therefore areas under the plasma level curves could be compared as indices of the bioavailability of disopyramide in the three preparations. Areas under the curves were divided by the actual mean dose of disopyramide base given, prior to the bioavailability comparison. $\mathrm{AUC}_{0 \rightarrow \infty}$ (in $\mathrm{mg} \mathrm{l}^{-1} \mathrm{~h}^{-1}$ ) per $\mathrm{mg}$

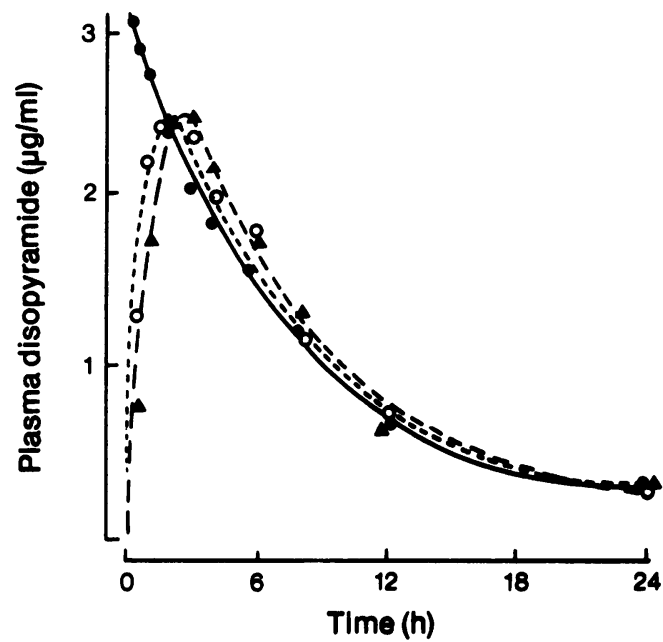

Figure 1 The mean time-courses of the plasma disopyramide concentrations produced by the three different disopyramide preparations studied. 10 i.v. disopyramide phosphate; $0---0$ oral disopyramide phosphate; $\Delta---\Delta$ oral disopyramide base).

Table 1 Disopyramide-pharmacokinetic parameters

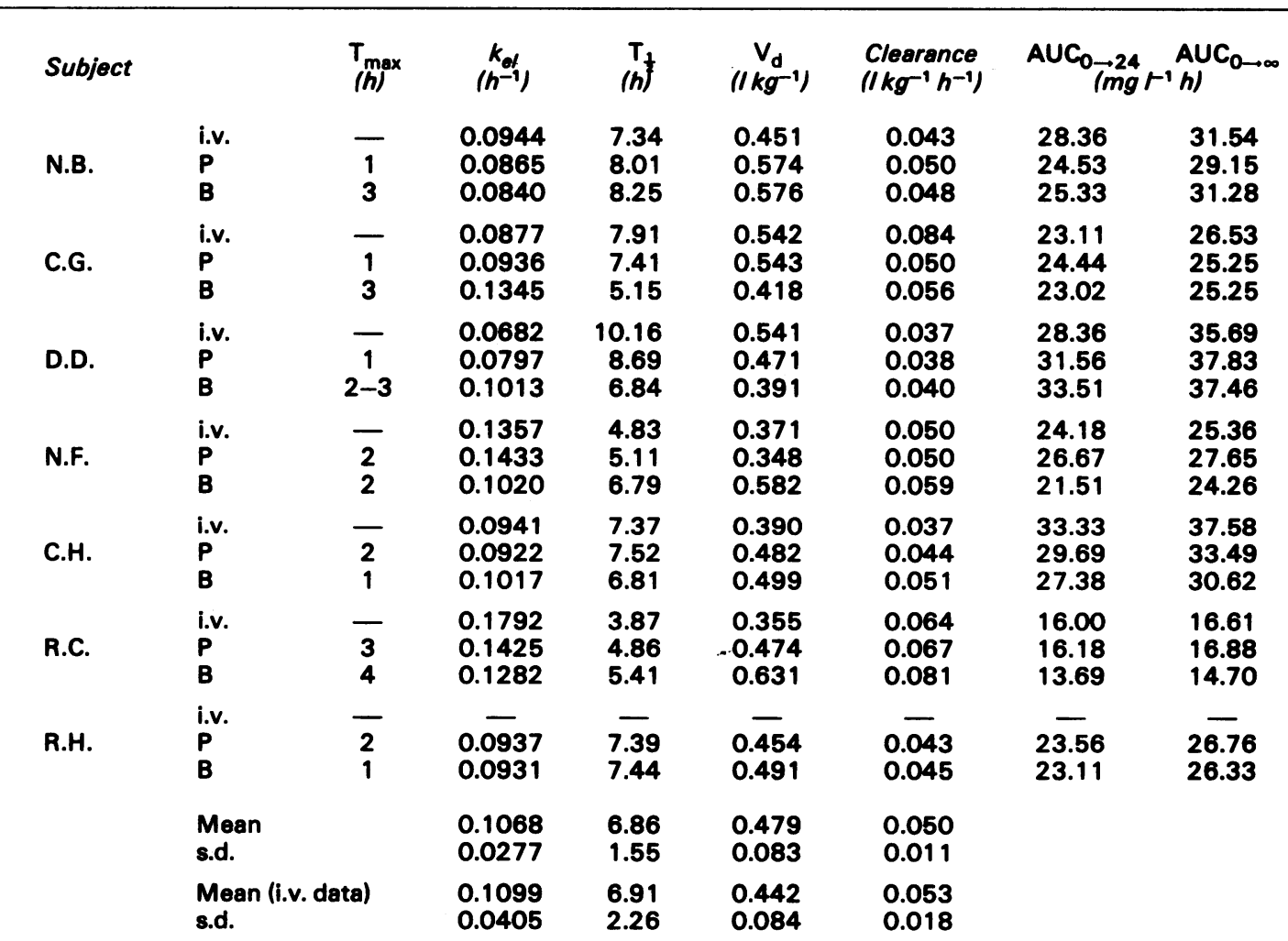

i.v. = i.v. disopyramide: $\mathbf{P}=$ oral disopyramide phosphate; $\mathbf{B}=$ oral disopyramide (base). 
disopyramide base given was $0.314 \pm 0.083$ for the intravenous base, $0.287 \pm 0.065$ for the oral phosphate and $0.262 \pm 0.069$ for the oral base. The differences in AUC were not statistically significant between the intravenous base and the oral phosphate $(t=2.007$; d.f. $=5 ; P>0.10$ ). Differences between the intravenous base and the oral base were statistically significant $(t=4.006 ;$ d.f. $=5 ; P<0.02)$, as were differences between the oral phosphate and oral base $(t=3.674$; d.f. $=6 ; P<0.02$ ).

The values of the pharmacokinetic parameters of disopyramide determined in the present study are generally similar to those obtained by Ranney, Dean, Karim \& Radzialowski (1971), who also analysed the behaviour of the drug in terms of a one-compartment model. These authors obtained mean values \pm s.e. mean of $0.11 \pm 0.02 \mathrm{~h}^{-1}$ for the terminal elimination phase rate constant, compared with $0.1068 \pm$ $0.0277 \mathrm{~h}^{-1}$ (mean \pm s.d.) in the present study; an apparent $V_{d}$ of $34.2 \pm 3.541 V_{d}$ (s.e. mean), compared with $0.442 \pm 0.0841 \mathrm{~kg}^{-1}$ (s.d.) in the present study (mean subject weight $73 \mathrm{~kg}$ ), and a total clearance of $3.71 \pm 0.671 \mathrm{~h}^{-1}$ (s.e. mean), whereas in the present study the clearance was $0.053 \pm 0.0181 \mathrm{~kg}^{-1} \mathrm{~h}^{-1}$ (s.d.). However, Hinderling \& Garrett (1976) found evidence that the kinetics of disopyramide were better described by a two compartment model. These authors determined pharmacokinetic parameters of the drug in relation to the concentration of disopyramide unbound in plasma. They found a rather greater terminal - elimination rate constant $\left(0.16 \pm 0.04 \mathrm{~h}^{-1}\right)$ and much higher values for the total volume of distribution and clearance.

Hinderling \& Garrett (1976) found an 86\% bioavailability for oral disopyramide, a finding in keeping with the conclusions of the present work. Although the present study suggested that oral disopyramide phosphate (91\%) had a rather higher bioavailability than the corresponding base (83\%), the bioavailability of the drug in both preparations was comparatively high, and for clinical purposes both preparations would probably be regarded as quite satisfactory, and virtually bioequivalent.

D.K. DUBETZ, N.N. BROWN, W.D. HOOPER, M.J. EADIE \& J.H. TYRER

Department of Medicine, University of Queensland Royal Brisbane Hospital, Brisbane, Australia

Received October 4, 1977

\section{References}

GIBALDI, M. \& PERRIER, D. (1975). Pharmacokinetics. New York: Marcel Dekker.

HINDERLING, P.H. \& GARRETT, E.R. (1976). Pharmacokinetics of the antiarrhythmic disopyramide in healthy humans. J. Pharmacokin. Biopharm., 4, 199-230.

HUTSELL, T.C. \& STACHELSKI, S.J. (1975). The determination of disopyramide and its mono- $\mathrm{N}$-dealkylated metabolite in blood serum and urine. J. Chromatog., 106, 151-158.

JAEGER, R.J. \& RUBIN, R.J. (1972). Migration of a phthalate ester plasticizer from polyvinylchloride blood bags into stored human blood and its localization in human tissues. New Engl. J. Med., 287, 1114-1118.

MARCEL, Y.L. \& NOEL, S.P. (1972). Contamination of blood stored in plastic packs. Lancet, i, 36-37.

ONO, K., TATSUKAWA, R. \& WAKIMOTO, T. (1975). Migration of plasticizer from hemodialysis blood tubing. J. Am. med. Ass., 234, 948-949.

RANNEY, R.E., DEAN, R.R., KARIM, A. \& RADZIALOWSKI, F.M. (1971). Disopyramide phosphate: pharmacokinetic and pharmacologic relationships of a new antiarrhythmic agent. Arch. Int. Pharmacodyn., 191, 162-188. 